\title{
Cyclic esotropia in a patient with unilateral traumatic aphakia: case report
}

\author{
M D COLE, A HAY, AND E M EAGLING \\ From the Birmingham and Midland Eye Hospital
}

SUMmary Cyclic esotropia is a rare and poorly understood condition normally treated by correcting the deviation measured on the squinting day. Control in some patients with this condition can be gained by correcting their refractive errors, thereby improving acuity. We report on an adult patient who developed cyclic esotropia after unilateral traumatic aphakia with failed contact lens wear whose squint was corrected by secondary intraocular lens implantation. This may be explained by the reduction in the degree of aneisokonia which subsequently improved stereopsis.

Cyclic esotropia is a rare and poorly understood disorder of ocular motility. Since the first report in 1958, ' many patients have been described. Other names for this condition are alternate day, or clock mechanism, esotropia. ${ }^{2}$ It has also been called circadian esotropia, ${ }^{3}$ but this does not accurately describe the condition correctly, as the word circadian means a daily or 24 hour change. Costenbader and Mousel $^{4}$ reviewed 3500 squint cases and found three that exhibited cyclical recurrence.

In most patients ${ }^{2}$ the condition occurs in childhood. On 'straight days' no anomalies of binocular vision are observed, though heterophoria may be present; on 'strabismic days' a large-angle esotropia will appear and sensory anomalies are often found. Diplopia is rare, and fusional amplitudes determined with the synoptophore are defective or absent. A 48hour cycle is encountered most commonly, but 72 hour and 96-hour cycles have been reported. The cyclic nature of the strabismus may last from four months to several years, after which the cycle breaks and esotropia becomes constant.

Surgery based on the amount of heterotropia as it occurs on the squinting days has been eminently successful in permanently curing this condition and re-establishing normal binocular functions. ${ }^{5}$

This report describes an adult patient with uniocular traumatic aphakia who subsequently developed cyclic esotropia. The squint was cured by capsulotomy and secondary intraocular lens implantation.

Correspondence to Mr M D Cole, FRCS, Birmingham and Midland Eye Hospital, Church Street, Birmingham B3 2NS.

\section{Case report}

A 24-year-old maintenance engineer first presented in November 1976 with an intraocular foreign body in his left eye from hammering a piece of machinery. The particle had penetrated the cornea and lens and was located posteriorly; it was removed with the giant magnet via a pars plana approach. A traumatic cataract slowly developed, which was aspirated four months later, and the vision corrected to 6/9. He was fitted with a hard contact lens, which was worn for about a year but was subsequently abandoned.

He failed to keep any further appointments until October 1984, when he returned after noticing that his left eye turned in intermittently over the previous 12 months. He recognised that there was a definite pattern. On day 1 he would squint all day. This continued until approximately midday on the following day, when the eyes became straight. The eyes remained straight for the rest of that day and the whole of the following day, only for the pattern to restart one day later. He did not recognise any diplopia during the squinting periods when asked directly. He had no previous history of a squint or amblyopia, and there was no family history of a squint. The patient was found to be right handed and right footed for all tasks. The posterior capsule had thickened during the previous period of absence, so that the corrected visual acuity in the aphakic eye had deteriorated to $<6 / 60$. A capsulotomy with the $\mathrm{Nd}$ YAG laser was performed. The subsequent orthoptic assessment was as follows:

In the squinting period (Fig. 1) the visual acuity 


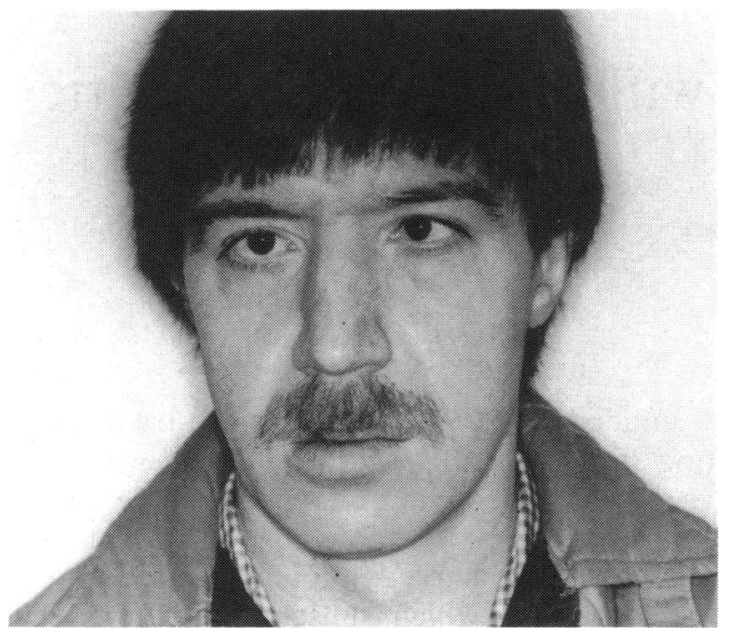

Fig. 1 Patient in squinting period.

was $6 / 4$ in the right eye with no correction (the refractive error in this eye was $+0.50 \mathrm{sph}$ with +0.50 cyl at $180^{\circ}$ ) and $6 / 7.5$ in the left with a $+12 \mathrm{D}$ sph lens (no near visual acuity was recorded). The cover test revealed a 50 PD (prism dioptre) left esotropia for near and distance and diplopia was recognised during the test. This was measured by the prism cover test and found to be 57 PD with a 2 PD right hypertropia. There was a full range of ocular movements. When the eyes converged the visual axes crossed and the two images could be joined. Further convergence caused the left eye to diverge.

Examination of the patient on the synoptophore showed that the objective angle was $+29^{\circ}$. There was also a right hypertropia of $2 \mathrm{PD}$. With a $+12 \mathrm{D}$ sph lens in front of the left eye, the subjective angle was not recordable, as the image from the left eye was suppressed. There was no demonstrable fusion.

On the following afternoon (Fig. 2) the visual acuity was 6/4 (N5) in the right eye and 6/6 in the left with a $+12 \mathrm{D}$ sph lens (N10 with +15 D sph). The cover test showed no deviation for near and a left microesotropia of $+2^{\circ}$ to $+3^{\circ}$ for distance. There was a full range of ocular movements. Binocular convergence was present to $10 \mathrm{~cm}$. The left eye then diverged resulting in diplopia.

Examination of the patient on the synoptophore with +12 D sph lens in front of the left eye showed that both the objective and subjective recording of the deviation was $+4^{\circ}$ with a right hypertropia of $1 \mathrm{PD}$. Fusion was demonstrable at $6^{\circ}$, showing a range of $10^{\circ}$ of convergence and $4^{\circ}$ of divergence. Simple stereopsis was appreciated, but the Wirt and Randot tests could not demonstrate this.

The patient was asked to keep a record of his

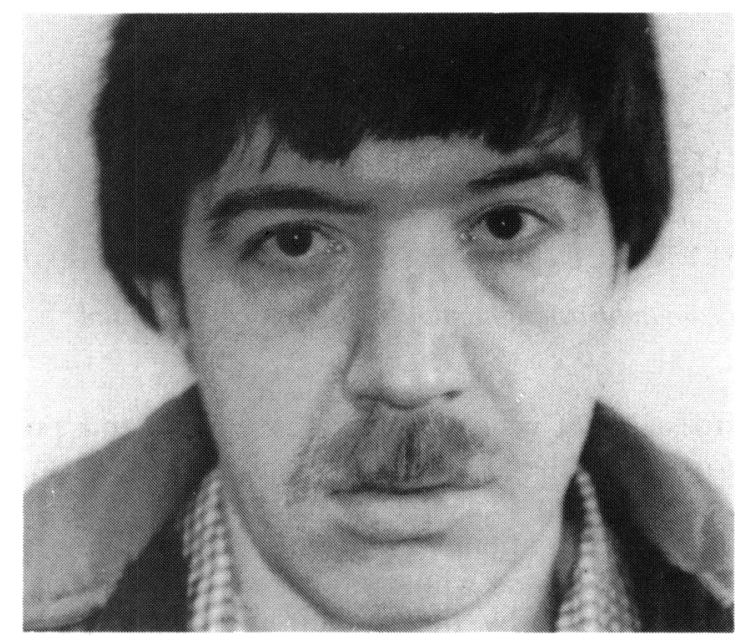

Fig. 2 Patient without squint.

squint. During the cycle he did not recognise any alterations in behaviour, mood, sleeping habits, temperature, frequency of micturition, libido, appetite, or sweating.

The visual acuity in his left eye was corrected with a soft contact lens to 6/12 (N8). This did not change the pattern of the squint, which remained the same for six months. The visual acuity in the right eye was $6 / 5$ (N5). The pattern then started to become more variable. He sometimes spent periods of three to four days either straight or squinting. A V pattern became more apparent, and on the squinting days the esotropia measured 40 PD for distance and 25 PD for near.

Four months later the pattern had changed to a left esotropia of 3-4 days' duration. Although the patient was young and the eye traumatised, it was decided to carry out a secondary implantation of a 19.0 dioptre anterior chamber flexible loop intraocular lens. This was because his occupation made contact lens wear difficult. The operation was performed in January 1985 , and the visual acuity in the left eye quickly improved to 6/9 (N8) unaided (this could be improved to $6 / 5$ with $-1 \cdot 25 \mathrm{D}$ sph). Postoperatively the squint became constant for 10 days, straightened for one day, then returned for one more day. The eye has remained straight ever since.

Six months later he is symptom free, with no complications. The orthoptic report is as follows.

The visual acuity in the right eye is $6 / 5$ (N5) and in the left eye 6/6 (N6) unaided. The cover test reveals a small esophoria for near and distance with rapid recovery. There is a full range of eye movements; binocular convergence is present to $6 \mathrm{~cm}$. The left eye subsequently diverges, resulting in diplopia. The 
esophoria when measured by the prism cover test is $2 \mathrm{PD}$ for near and $1 \mathrm{PD}$ for distance. The prism fusion range is $30 \mathrm{PD}$ base out, and $10 \mathrm{PD}$ base in for near; and 25 PD base out, and 4 PD base in for distance. Stereopsis has a resolution of $240^{\prime \prime}$ of arc when measured with the TNO (random dot stereogram) test.

Ocular examination found the lens nicely positioned in the anterior chamber with a clear central gap in the posterior capsule. The intraocular pressures, optic discs, and fundi were normal.

\section{Discussion}

Cyclic esotropia is a strabismus which is present on one day and absent on the next and so on, thus showing a 48-hour cycle. ${ }^{2}$ It is unrelated to visual acuity, accommodation, fatigue, and non-fusion. It is usually accompanied by suppression and poor binocular vision. Helveston ${ }^{6}$ outlined the characteristics of a typical patient (Table 1). He recorded only one adult aged 32.

Variations in the timing of the cycle are common, and the cycle often becomes more prolonged with time. Our patient was atypical, though, in that he recognised diplopia during the cover test in the squinting period. This may be because the squint developed in adulthood, and binocular vision developed normally in childhood. It is also unusual to demonstrate a manifest deviation at all in the so called non-squinting period.

Consecutive cyclic esotropia has been recorded, ${ }^{78}$ and there has been one reported case of cyclic hypertropia. ${ }^{3}$ Troost et al. ${ }^{9}$ recorded an adult case following retinal detachment surgery. Both our patient and the one reported by Troost et al. ${ }^{9}$ developed the squint after a disturbance of acuity in one eye sometime after the event. Apart from the operations involved there appear to be no other precipitating factors. No previous history or family history of a squint existed. The visual acuity in Troost and colleagues' patient was restored to normal. ${ }^{9}$ There was a cyclical pattern of pupillary dilatation on the affected side which persisted when the squint appeared along with a blepharoptosis. These changes

Table 1 Average characteristics of cyclic esotropia

\begin{tabular}{|c|c|}
\hline $\begin{array}{l}\text { Onset } \\
\text { Deviation } \\
\text { Vertical incomitance }\end{array}$ & $\begin{array}{l}\text { Three to four years } \\
30 \text { to } 40 \text { PD (prism dioptres) esotropia } \\
\text { Mild V pattern }\end{array}$ \\
\hline Refraction & With or without $2 \cdot 25 \mathrm{D}$ sph hypermetropia \\
\hline Vision & With or without amblyopia \\
\hline AC/A ratio & May be high \\
\hline Response to glasses & May fuse with glasses (with or without bifocals) \\
\hline Response to surgery & Usually fuses after surgery \\
\hline Usual cyclic pattern & 48 Hours \\
\hline
\end{tabular}

were thought to be due either to a periodic sympathetic hyperactivity during the esotropic day or to some cyclic oculomotor nerve dysfunction.

Helveston ${ }^{6}$ commented on the similarity between cyclic esotropia and a decompensated accommodative squint. Windsor and Berg ${ }^{3}$ thought that cyclic esotropia represented a slow motion development of a concomitant squint. However, these all refer to childhood cases.

Kubuta and Harada ${ }^{10}$ believe that the essential characteristic of cyclic esotropia is a sixth nerve palsy. They demonstrated this by electromyography. Williams and Normandin" presented a case of a 7year-old child who was struck by a car and rendered unconscious. He subsequently developed a bilateral sixth nerve palsy with a cyclic esotropia.

24-Hour cycles are well known in medicine. ${ }^{12}$ However, our understanding of the cyclic mechanism remains speculative. It is known that some children show regular 48-hour cycles in body temperature, pulse rate, and other physiological functions. In adults, alternate-day cycles may show in changes in behaviour, moods, or physiological functions, including depression, schizophrenia, or sleep patterns. Transition between phases tend to be sharp 'as if a switch has been thrown'. ${ }^{2}$ They may follow head trauma, high fever, cerebrovascular disease, syphilis, or encephalitis. Richter ${ }^{12}$ points out that the appearance of these cycles in psychiatry is always secondary to the presence of a basic illness. Work with rats has shown that lesions in the hypothalamus may disrupt the clock mechanism. Richter postulated that in man the superior colliculi or the oculomotor nuclei could be defective. He suggests that patients with cyclic esotropia have a more deeply rooted biological abnormality than is apparent by their squint alone - that is, the squint may be the only outward manifestation of a more basic disturbance. The supposition is strengthened by previous observation in a small number of patients. Thus, in-phase changes in behaviour have been reported by Chamberlain ${ }^{13}$ in one patient and Roper-Hall and Yapp $^{14}$ in six. The latter investigators also noticed electroencephalographic (EEG) changes in two patients and increased frequency of micturition in one patient during the squinting phase. Investigation of various biological parameters including psychological tests, serial EEGs, urinary excretion products, pulse rate, body temperature, urine volume, and frequency of micturition by Friendly et al..$^{15}$ in one patient and similar studies performed by RoperHall in collaboration with Yenner failed to reveal a more deeply rooted 48 -hour clock mechanism. A child with minimal brain dysfunction who developed cyclic esotropia was also investigated by Gadroth $e t$ al. ${ }^{16}$ to assess the hypothalamic-pituitary axis and the 
sleep cycle, but no abnormal function was detected.

Roper-Hall and Yapp $^{14}$ also noticed that in three out of eight of these patients there was incomplete or unusual cerebral dominance. A strong family history is often observed. In our patient on direct questioning no behavioural or physiological changes mentioned above were observed. He consistently preferred to use his right hand and foot for all tasks.

Surgery based on the full amount of heterotropia as it occurs on the day of squinting has been successful in permanently curing the condition. This success favours the hypothesis that these patients are basically strabismic, and by some unknown mechanism capable of maintaining normal binocular vision during the cycle. Various authors ${ }^{3-51314}$ have reported successful results with this form of treatment.

Helveston $^{6}$ collected 13 patients by sending a questionnaire to 61 ophthalmologists with an interest in strabismus. He found five patients who had been treated successfully by correcting their refractive error (two patients had a high accommodative convergence/convergence (AC/A) ratio requiring bifocals). So it seems that improving acuity or reducing the accommodation in those with high $\mathrm{AC} / \mathrm{A}$ ratios can help the patient to control the squint. However, treatment of patients with amblyopia by occlusion has tended to convert the squint into a permanent esotropia.

This case is unique in that the improvement in acuity from 6/12 (N8) to 6/6 (N6) in the left eye, and reduction of aneisokonia by secondary lens implantation in an aphakic eye, have corrected the squint. The image size magnification with the aphakic eye corrected with a contact lens is approximately $8 \%$, whereas the magnification with an intraocular lens is negligible. ${ }^{17}$ It would appear that the resultant improvement in stereopsis has re-established binocular control in a patient presumed to have developed normal binocular vision in childhood.

The trigger zone causing cyclic esotropia could be located in a number of anatomical sites. It may lie within the oculomotor nuclei or their interconnections,${ }^{12}$ or it may lie within the sensory pathways that effectively control the oculomotor nuclei. In view of the response to treatment the trigger in this patient must lie within the sensory pathways. The prior development of normal binocular vision may be required to establish control by this method.

In conclusion, if uniocular acuity or binocular vision can be improved in patients with cyclic esotropia, this should be attempted before resorting to conventional squint surgery.

The authors thank K R Whale, E A Howrie, and H E Willshaw for constructive criticism of this paper.

\section{References}

1 Burian HM. Round table discussion. In: Allen $\mathrm{JH}$, ed Strabismic ophthalmic symposium. St Louis: Mosby, 1958: 488.

2 Von Noorden GK. Binocular vision and ocular motility. Toronto: Mosby, 1985: 385-6.

3 Windsor CE, Berg EF. Circadian heterotropia. Am J Ophthalmol 1981; 91: 8-13.

4 Costenbader FD, Mousel DK. Cyclic esotropia. Arch Ophthalmol 1964; 71: 88-9.

5 Helveston EM. Surgical treatment of cyclic esotropia. Am Orthopt J 1976; 26: 87-8.

6 Helveston EM. Cyclic strabismus. Am Orthopt J 1973; 23: 48-51.

7 Uemura Y, Tomita M, Tanaka Y. Consecutive cyclic esotropia. J Pediatr Ophthalmol Strabismus 1977; 14: 278-80.

8 Munchnick RS, Sanflippo S, Dunlap EA. Cyclic esotropia developing after strabismus surgery. Arch Ophthalmol 1976; 94: 459-61.

9 Troost BT, Abel L, Noreika J, Genovese FM. Acquired cyclic esotropia in an adult. Am J Ophthalmol 1981;91: 8-13.

10 Kubota N, Harada M. Cyclic esotropia. Nippon Ganka. Gakkai Zasshi 1962; 68 (suppl): 297-302.

11 Williams F, Normandin V. Case study: traumatic bilateral lateral rectus muscle paresis vs. traumatic cyclic esötropia. Am Orthopt J 1976; 26: 102-3.

12 Richter CP. Clock-mechanism esotropia in children. Bull Johns Hopkins Hosp 1968; 122: 218-23.

13 Chamberlain W. Cyclic esotropia. Am Orthopt J 1968; 18: 31-4.

14 Roper-Hall MJ, Yapp JMS. Alternate day squint. In: Kimpson H, ed. First International Congress of Orthoptics. St Louis: Mosby, 1968: 262-71.

15 Friendly DS, Manson RA, Albert DG. Cyclic strabismus-a case report. Doc Ophthalmol 1973; 34: 189-202.

16 Gadoth N, Dickerman Z, Lerman M, Lavie P. Cyclic esotropia with minimal brain dysfunction. J Pediatr Ophthalmol Strabismus 1981; 18: 14-6.

17 Wilensky J. Intraocular lens. In: Peyman GA, Sanders DR, Goldberg MF, eds. Principles and practice of ophthalmology. Philadelphia: Saunders, 1980: 634-6.

Accepted for publication 10 February 1987. 